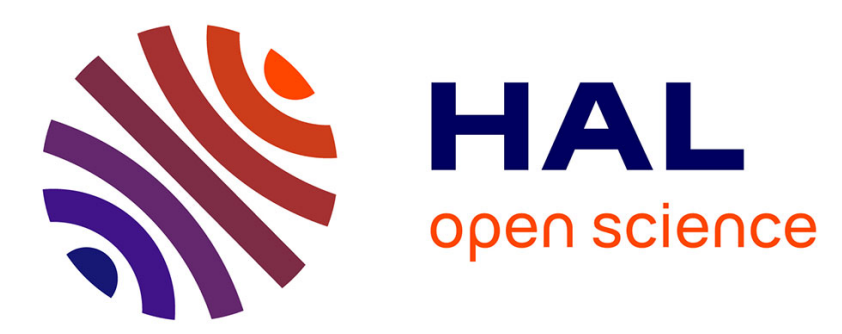

\title{
Cistrome of the aldosterone-activated mineralocorticoid receptor in human renal cells
}

Florian Le Billan, Junaid A. Khan, Khadija Lamribet, Say Viengchareun, Jrôme Bouligand, Jérôme Fagart, Marc Lombès

\section{To cite this version:}

Florian Le Billan, Junaid A. Khan, Khadija Lamribet, Say Viengchareun, Jrôme Bouligand, et al.. Cistrome of the aldosterone-activated mineralocorticoid receptor in human renal cells. FASEB Journal, 2015, 10.1096/fj.15-274266 . hal-03464093

\section{HAL Id: hal-03464093 \\ https://hal.science/hal-03464093}

Submitted on 3 Dec 2021

HAL is a multi-disciplinary open access archive for the deposit and dissemination of scientific research documents, whether they are published or not. The documents may come from teaching and research institutions in France or abroad, or from public or private research centers.
L'archive ouverte pluridisciplinaire $\mathbf{H A L}$, est destinée au dépôt et à la diffusion de documents scientifiques de niveau recherche, publiés ou non, émanant des établissements d'enseignement et de recherche français ou étrangers, des laboratoires publics ou privés. 


\title{
Cistrome of the aldosterone-activated mineralocorticoid receptor in human renal cells
}

\author{
Florian Le Billan, ${ }^{* \dagger}$ Junaid A. Khan, ${ }^{*}{ }^{\dagger, 1}$ Khadija Lamribet, ${ }^{*}{ }^{\dagger}$ Say Viengchareun, ${ }^{*}, \dagger$ \\ Jérôme Bouligand, ${ }^{,},{ }^{\dagger}+$ Jérôme Fagart, $*,+, 2,3$ and Marc Lombès ${ }^{*}, \dagger, \S, 2,3$ \\ *Unité 1185, Institut National de la Santé et de la Recherche Médicale, Le Kremlin-Bicêtre, France; \\ ${ }^{\dagger}$ Faculté de Médecine Paris-Sud, Unité Mixte de Recherche-S1185, Université Paris-Sud, Le Kremlin- \\ Bicêtre, France; and `Service de Génétique Moléculaire, Pharmacogénétique et d’Hormonologie and \\ ${ }^{\S}$ Service d'Endocrinologie et des Maladies de la Reproduction, Hôpital de Bicêtre, Assistance \\ Publique-Hôpitaux de Paris, Le Kremlin Bicêtre, France
}

\begin{abstract}
Aldosterone exerts its effects mainly by activating the mineralocorticoid receptor (MR), a transcription factor that regulates gene expression through complex and dynamic interactions with coregulators and transcriptional machinery, leading to fine-tuned control of vectorial ionic transport in the distal nephron. To identify genomewide aldosterone-regulated MR targets in human renal cells, we set up a chromatin immunoprecipitation (ChIP) assay by using a specific anti-MR antibody in a differentiated human renal cell line expressing green fluorescent protein (GFP)-MR. This approach, coupled with highthroughput sequencing, allowed identification of 974 genomic MR targets. Computational analysis identified an MR response element (MRE) including single or multiple half-sites and palindromic motifs in which the AGtACAgxatGTtCt sequence was the most prevalent motif. Most genomic MR-binding sites (MBSs) are located $>10 \mathrm{~kb}$ from the transcriptional start sites of target genes $(84 \%)$. Specific aldosterone-induced recruitment of MR on the first most relevant genomic sequences was further validated by ChIPquantitative (q)PCR and correlated with concomitant and positive aldosterone-activated transcriptional regulation of the corresponding gene, as assayed by RT-qPCR. It was notable that most MBSs lacked MREs but harbored DNA recognition motifs for other transcription factors (FOX, EGR1, AP1, PAX5) suggesting functional interaction. This work provides new insights into aldosterone MR-mediated renal signaling and opens relevant perspectives for mineralocorticoid-related pathophysiology.-Le Billan, F., Khan, J. A., Lamribet, K., Viengchareun, S., Bouligand, J., Fagart, J., Lombès, M. Cistrome of the aldosterone-activated mineralocorticoid receptor in human renal cells. FASEB J. 29, 000-000 (2015). www.fasebj.org
\end{abstract}

Key Words: chromatin immunoprecipitation sequencing • sodium $\cdot$ nuclear receptor $\cdot$ transcription factor

Abbreviations: $\alpha \mathrm{ENaC}$, epithelial sodium channel, $\alpha$-subunit; AP-1, activated protein 1; AR, androgen receptor; BSA, bovine serum albumin; CCD, convoluted collecting duct; ChIP, chromatin immunoprecipitation; ChIP-seq, sequencing of ChIPenriched fragments; DBD, DNA-binding domain; EGR1, early growth response protein 1; ERGIC1, endoplasmic reticulum-

(continued on next page)
ALDOSTERONE, THE MAIN MINERALOCORTICOID HORMONE in humans, plays a critical role in maintaining sodium homeostasis by regulating sodium reabsorption within the distal collecting duct of the nephron (1). This steroid hormone primarily exerts its genomic effects by binding to and activating the mineralocorticoid receptor (MR), a ligand-induced transcription factor belonging to the nuclear receptor superfamily (2). In the absence of hormone, MR has been shown to be located mainly in the cytoplasm, as a part of a heat shock protein (HSP)-containing heterooligomeric complex. Aldosterone binding to MR leads to a conformational change in the receptor, triggering its nuclear translocation. Thus, it has been proposed that the aldosterone-MR complex binds, as a dimer, to specific DNA sequences, so-called hormone response elements (HREs), located in the regulatory sequences of target genes. Subsequent recruitment of the basal transcriptional machinery, as well as several transcriptional coregulators, leads to fine-tuned regulation of gene transcription.

Altered mineralocorticoid signaling pathways have been documented in numerous human diseases, such as arterial hypertension and cardiovascular and kidney diseases. Thus, a better understanding of renal mineralocorticoid signaling requires identification of aldosterone-regulated genes and characterization of fine-tuned molecular mechanisms of gene transactivation. During the past decades, intensive research on MR target genes in several mineralocorticoid-sensitive tissues or cells has led many laboratories to develop various experimental approaches, including SAGE (3), microarrays (4), and transcriptomics (5). These approaches aided in the description of important aldosterone-regulated effectors, most notably those involved in sodium reabsorption in animal and cell models. For instance, the transcriptional regulation of classic MR target genes, such as sodium channel, non-voltage-gated 1

\footnotetext{
${ }^{1}$ Current affiliation: Institute of Pharmacy, Physiology and Pharmacology, University of Agriculture, Faisalabad, Pakistan.

${ }^{2}$ These authors contributed equally to this work.

${ }^{3}$ Correspondence: INSERM U1185, Faculté de Médecine Paris-Sud, Université Paris-Sud, 63 rue Gabriel Péri, 94276, Le Kremlin-Bicêtre, France. E-mail: marc.lombes@u-psud.fr (M.L.); jerome.fagart@inserm.fr (J.F.)

doi: $10.1096 /$ fj.15-274266

This article includes supplemental data. Please visit $h t t p: / /$ www. fasebj.org to obtain this information.
} 
alpha (SCNN1A), encoding for the $\alpha$-subunit of the epithelial sodium channel $(\alpha \mathrm{ENaC})$, was first identified in the distal convoluted tubule (6) and was subsequently studied by measuring the activity of a promoter construct containing MR response elements (MREs) linked to a reporter gene (7). Afterward, SAGE was performed on aldosteronetreated cells from the distal convoluted tubule and identified new aldosterone target genes, such as serum glucocorticoid kinase 1 (SGK1) and glucocorticoid-induced leucine zipper ( $\operatorname{GILZ})(3,8)$. More recently, Fakitsas et al. (4) identified 9 new aldosterone-activated genes, including ubiquitin-specific protease 2-45 (USP2-45), by using a DNA microarray approach on complementary DNAs obtained from mouse distal nephron segments. Another group identified and characterized the gene connector enhancer of kinase suppressor of ras 3 (CNKSR3), as an aldosterone target with renal activity, by using chromatin immunoprecipitation (ChIP) and reportercoupled mutated promoter approaches (9). All these results were validated at the transcriptional level by quantitative (q) PCR and Northern blot analysis and at the protein level by Western blot analysis. These new approaches have decidedly improved understanding of the mechanistic aspects of the renal MR pathway and have integrated that knowledge into the understanding of the mechanisms of transepithelial electrolytic transport.

In an effort to undertake a more comprehensive assessment of MR genomic targets in the human kidney, we took advantage of the ChIP assay followed by deep highthroughput sequencing (ChIP-seq). For the first time, we applied ChIP-seq analysis to acute aldosterone exposure to identify the genome-wide MR-binding regions in a human aldosterone-sensitive renal cell line (10) using a recently generated anti-MR antibody (11). Thus, we set up an exhaustive genomic mapping of MR binding sites (MBSs) on approximately 1000 sequences, allowing extensive description of a consensus MRE motif. Furthermore, novel aldosterone target genes were identified correlating genomic MR occupancy and target gene transactivation. This first ChIP-Seq analysis on human cells and appropriate

\section{(continued from previous page)}

Golgi intermediate compartment; FAM65B, family with sequence similarity 65, member B; FBS, fetal bovine serum; FKBP5, FK506 binding protein; FOX, forkhead box; GR, glucocorticoid receptors; GRE, glucocorticoid response element; HRE, hormone response element; HSP, heat shock protein; IGV, integrative genome viewer; LINC00963, long intergenic non-protein-coding RNA 963; MACS, model-based analysis for ChIP-seq; MBS, MR-binding site; MR, mineralocorticoid receptor; MRE, mineralocorticoid response elements; NFATC2, nuclear factor of activated T-cells, cytoplasmic, calcineurindependent 2; NFKBIA, nuclear factor of kappa light polypeptide gene enhancer in B-cells inhibitor, alpha; PAX5, paired box protein 5; PER1, period circadian protein homolog 1; PIC, protease inhibitor cocktail; PR, progesterone receptor; PTPN1, protein tyrosine phosphatase, non-receptor type 1; qPCR, quantitative PCR; RNA pol II, RNA polymerase II; SCNN1A, sodium channel, non-voltage-gated 1 alpha; SERPINE1, serpin peptidase inhibitor, clade $\mathrm{E}$ (nexin, plasminogen activator inhibitor type 1), member 1; SGK1, serum glucocorticoid kinase 1; SRC1, steroid receptor coactivator 1; TBS-T, Tris-buffered salineTween; TPRG1, tumor protein p63 regulated 1; TSS, transcription start site; $Z B T B 16$, zinc finger and BTB domain containing 16; ZMYND8 zinc finger, MYND-type containing 8 experimental tools undoubtedly helped deepen our understanding of renal mineralocorticoid signaling and provided new insights into how MR participates in the hormonal control of the ion vectorial transport.

\section{MATERIALS AND METHODS}

Aldosterone, protease inhibitor cocktail (PIC), and Laemmli buffer were purchased from Sigma-Aldrich (Lyon, France). DMEM high glucose with L-glutamine medium, trypsin, G418, Fast SYBR Green Master Mix buffer, random primers, dNTP, and Superscript reverse polymerase were purchased from Life Technologies (Saint-Aubin, France). PBS and penicillin-streptomycin solution were purchased from GE Healthcare (Vélizy-Villacoublay, France). Western blot equipment was purchased from Bio-Rad (Marnes-la-Coquette, France).

Purified rabbit polyclonal $39 \mathrm{~N}$ antibody was raised against the first amino acids (1-18) at the $\mathrm{N}$ terminus of the human MR (11). Rabbit anti-SRC1 antibody was from Santa Cruz Biotechnology (Santa Cruz, CA, USA), mouse anti-polymerase II antibody was from Millipore (Paris, France), and control unrelated antibody was from the HighCell\# ChIP kit (Diagenode, Seraing, Belgium).

\section{Cell Culture}

Human kidney GFP-hMR cells or parental cells [HK-GFP-MR or HK $(10,12)]$ were routinely cultured at $37^{\circ} \mathrm{C}$, in a humidified incubator gassed with $5 \% \mathrm{CO}_{2}$, seeded on Petri dishes (BP100) with $10 \mathrm{ml}$ of DMEM (high-glucose medium with L-glutamine) containing $2.5 \%$ fetal bovine serum (FBS) (Biowest, Courtaboeuf, France), $100 \mathrm{U} / \mathrm{ml}$ penicillin, and $100 \mu \mathrm{g} / \mathrm{ml}$ streptomycin. For the HK-GFP-MR cells, the medium was supplemented with geneticin $(200 \mu \mathrm{g} / \mathrm{ml})$.

\section{ChIP}

Five days before the experiments, geneticin was removed from the cell medium. Twenty-four hours before hormonal treatment, complete medium was removed, HK-GFP-MR cells were washed twice with $5 \mathrm{ml}$ PBS and incubated with steroid-free medium (dextran-coated charcoal medium), containing $2.5 \%$ dextrancoated charcoal-treated FBS. The next day, the cells were treated for $1 \mathrm{~h}$ at $37^{\circ} \mathrm{C}$ with $100 \mathrm{nM}$ aldosterone or the same amount of vehicle (ethanol).

Treated cells were fixed with $1 \%$ paraformaldehyde (Electron Microscopy Sciences, Saint-Germain-en-Laye, France) for $10 \mathrm{~min}$ at room temperature. Paraformaldehyde fixation was quenched with $0.125 \mathrm{M}$ glycine for $8 \mathrm{~min}$. The cells were washed twice with ice-cold PBS. Cell lysis and chromatin shearing were performed with the HighCell\# ChIP kit (Diagenode) buffers, according to the manufacturer's recommendations, with the following modifications: chromatin shearing was performed in $500 \mu \mathrm{l}$ shearing buffer $\mathrm{S} 1+$ protease inhibitor mix, applying 2 runs of 10 cycles at high intensity (Bioruptor; Diagenode). Each cycle was composed of $30 \mathrm{~s}$ with effective application of ultrasounds $(\mathrm{ON})$ and $30 \mathrm{~s}$ without $(\mathrm{OFF})$. Between each run, heated water was replaced by ice-cold water and ice. Concentrations of sheared chromatin protein were measured, using the bicinchoninic acid assay (Interchim, Montluçon, France) on a spectrophotometer Victor3 (Perkin Elmer, Courtabœuf, France), in parallel with a bovine serum albumin (BSA) standard range (Interchim).

Protein A-coated magnetic beads ( $25 \mu \mathrm{l}$ of the stock suspension) were washed 3 times in buffer $\mathrm{C} 1$ and resuspended in $\mathrm{C} 1$ buffer supplemented with $1 \%$ PIC (100 $\mu$ l final volume). Sheared chromatin (total amount of $1.3 \mathrm{mg}$ protein) and $7 \mu \mathrm{g}$ of one of the tested antibodies were then added to the beads and the final volume was adjusted to $500 \mu \mathrm{l}$ with $\mathrm{C} 1$ buffer supplemented with 
$1 \%$ PIC and $0.1 \%$ BSA (final concentrations). Samples were incubated overnight at $4^{\circ} \mathrm{C}$ with a rotary incubator. Magnetic beads were then isolated and washed 3 times with $\mathrm{Cl}$ buffer and once with W1 buffer. DNA fragments from the immunoprecipitated chromatin were eluted with the DNA isolation buffer supplemented with $1 \%$ proteinase $\mathrm{K}$ for $15 \mathrm{~min}$ at $55^{\circ} \mathrm{C}$ and finally for $15 \mathrm{~min}$ at $100^{\circ} \mathrm{C}$. Isolated DNA fragments were then sequenced (ChIP-Seq) or quantified by real-time qPCR.

\section{cDNA libraries and ChIP sequencing}

Library preparation and Illumina (San Diego, CA, USA) sequencing were performed at the Ecole Normale Supérieure Genomic Platform (ENS, Paris, France). Libraries were prepared by using NEXTflex ChIP-Seq Kit (Bioo Scientific, Saint Marcel, France), with $1 \mathrm{ng}$ IP or input DNA. The libraries were multiplexed by 6 on 1 flow cell lane. A 50 bp read sequencing was performed on a HiSeq 1500 device (Illumina).

\section{ChIP-seq bioinformatics analysis and data managing}

The analyses were performed with the Eoulsan pipeline (13), including read filtering and mapping, alignment filtering, and formatting. Before mapping, poly-N read tails were trimmed, reads $\leq 11$ bases were removed, and reads with quality mean $\leq 12$ were discarded. Reads were then aligned against the Human Genome version 19 (hg19) annotation [Genome Reference Consortium; National Center for Biotechnology Information (NCBI), Bethesda, MD, USA] using Bowtie (ver. 0.12.9) (14). Alignments from reads matching more than once on the reference genome were removed by using the Java version of SAMtools (15). PCR duplicates were filtered out with the MarkDuplicates tool of the Picard suite (http://broadinstitute.github.io/picard/; Broad Institute, Cambridge, MA, USA) and the peak calling step was performed with Modelbased Analysis for ChIP-seq (MACS; ver. 1.4.2) (16). The raw fastq files are available on the GEO repository (www.ncbi.nlm.nih.gov/ geo/; NCBI; accession number in progress).

Sequencing data were analyzed with the MACS software (17), available on the online platform Nebula (Curie Institute, Paris). MACS aligned all the read sequences on the reference hg19. This alignment allowed comparison between the DNA fragments obtained from aldosterone-treated and vehicle samples, permitting selection of the most significant MR genomic fixation sites (peaks). A peak was considered significant when it differed from the background signal with $P \geq 10^{-5}$. For each site, MACS calculated a score that corresponds to $-10 \log (P)$. MACS classified the significant sites on a spreadsheet containing related information [chromosome, position, score, name of the nearest gene, distance from transcription start site (TSS), and type region)]. The Integrative Genomic Viewer software (IGV) was used to visualize the DNA fragment alignment on hg19 and to select the DNA sequence of the significant sites. Identification of the MRE within significant

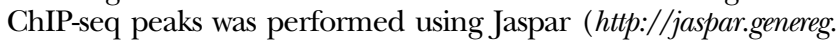
net/) (18) and FIMO (http://meme-suite.org/tools/fimo) software. The resemblance between the identified MRE was monitored by using the Weblogo website (http://weblogo.berkeley.edu/logo.cgi; University of California, Berkeley, Berkeley, CA, USA) (19). Identification of half-MRE and other motifs was performed using the MEME suite web server (http://meme-suite.org/tools/meme).

\section{Primer design for genomic amplification and RT- qPCR assays}

Primer pairs encompassing significant MBSs were designed by using NCBI's software Primer BLAST (http://www.ncbi.nlm. nih.gov/tools/primer-blast/; NCBI). Amplicon length was kept between 80 and 130 bp. Primers were from Eurogentec ( $w w w$. eurogentec.com), purified by the selective precipitation optimized process (SePOP), desalted, and delivered at $100 \mu \mathrm{M}$ concentration in water.

\section{qPCR}

ChIP-resulting DNA samples were amplified by real-time qPCR, by using the QuantStudio 6 Flex System (Life Technologies), with a $5 \mu \mathrm{l}$ DNA sample, $6 \mu \mathrm{l}$ fluorescent buffer Fast SYBR Green Master Mix, and $0.5 \mu \mathrm{l}$ forward and reverse primers (300 nM final) (primer sequences are provided in Supplemental Table $\mathrm{S} 1$ ). After $10 \mathrm{~min}$ preincubation at $95^{\circ} \mathrm{C}, 40$ cycles were run. Each cycle was composed of $15 \mathrm{~s}$ denaturation phase at $95^{\circ} \mathrm{C}$, followed by 1 min hybridization and amplification phase at $60^{\circ} \mathrm{C}$. Each DNA sample was analyzed in triplicate. All results are expressed as a percentage of input (Percent Input Method, ChIP analysis; Life Technologies) and expressed as means \pm sEM of 3 independent experiments.

\section{RT- and real-time-qPCR}

Treated HK-GFP-MR cells were washed twice with ice-cold PBS. Total RNA was extracted by the guanidium isothiocyanate +phenol-chloroform method, with the TRI reagent (Molecular Research Center, Inc., Euromedex, Mundolsheim, France), according to the manufacturer's recommendations. The RNA pellet was dissolved in $20 \mu$ l water and quantified with a Nanodrop spectrophotometer (Thermo Scientific, Villebon, France). Total RNA $(1 \mu \mathrm{g})$ was incubated for $10 \mathrm{~min}$ at $37^{\circ} \mathrm{C}$ with $0.5 \mu \mathrm{l}$ DNase I (Biolabs, Evry, France) in a total volume of $10 \mu$ l to remove potential genomic DNA, followed by a $10 \mathrm{~min}$ incubation at $75^{\circ} \mathrm{C}$ with $1 \mu l 25$ mM EDTA (Life Technologies). For each sample, $9 \mu \mathrm{l}$ RT mix was incubated in the presence of Superscript reverse transcriptase $(1 \mu \mathrm{l})$, random primers $(2 \mu \mathrm{l}), 10 \mathrm{mM} \mathrm{dNTP}(0.8 \mu \mathrm{l})$, $10 \times$ RT buffer $(2 \mu \mathrm{l})$, and water $(3.2 \mu \mathrm{l})$. After enzymatic activation for $10 \mathrm{~min}$ at $25^{\circ} \mathrm{C}$, RT was performed for $2 \mathrm{~h}$ at $37^{\circ} \mathrm{C}$, and the transcriptase was rapidly denatured at $85^{\circ} \mathrm{C}$. Real-time qPCR was performed on the cDNA, as described above. Specific primer sequences are provided in Supplemental Table S2. A 10th dilution standard range was run in parallel to quantify cDNA [attomole amount $=f\left(C_{\mathrm{t}}\right.$ value $\left.)\right]$. All samples were quantified in duplicate. Relative expression in a given sample was normalized to the internal reference rRNA $18 \mathrm{~S}$ values, where the control condition values are arbitrarily set at 1 . The results are expressed as means \pm SEM.

\section{Protein quantification and Western blot analysis}

Total protein extracts were prepared from treated HK-GFP-MR cells, using the protein extraction buffer $[150 \mathrm{mM} \mathrm{NaCl}, 50 \mathrm{mM}$ Tris-HCl (pH 7.5), 0.5 mM EDTA, $30 \mathrm{mM}$ sodium pyrophosphate, and $50 \mathrm{mM} \mathrm{NaF}$, extemporaneously supplemented with $1 \%$ Triton X-100 (Sigma-Aldrich), 1\% PIC 100×, and 0.1\% SDS. Samples were kept at $4^{\circ} \mathrm{C}$ for $30 \mathrm{~min}$ and then centrifuged at $16,000 \mathrm{~g}$ for $20 \mathrm{~min}$ at $4^{\circ} \mathrm{C}$. The supernatant was resuspended in water, and the protein concentrations were quantified with the bicinchoninic acid assay.

MR immunoprecipitation was performed from $500 \mu \mathrm{g}$ total proteins with anti-MR $39 \mathrm{~N}$ antibody $(7 \mu \mathrm{g}), 0.1 \%$ BSA, $1 \%$ PIC $100 \times, 100 \mu \mathrm{l}$ washed protein-A-coated magnetic beads (from $25 \mu$ l of the stock solution; HighCell\# ChIP kit; Diagenode) and C1 buffer in a total volume of $500 \mu \mathrm{l}$. After an overnight incubation at $4^{\circ} \mathrm{C}$, the supernatants were removed, and the immunoprecipitated proteins were eluted from magnetic beads after addition of $4 \times$ Laemmli buffer and incubation at $95^{\circ} \mathrm{C}$ for $5 \mathrm{~min}$. Fifty 
micrograms of the proteins was processed in parallel runs for immunoblot analysis and considered to be input samples.

The samples were electrophoresed in a Trans-Blot SD tank (Bio-Rad), first into a concentration gel for $20 \mathrm{~min}$ at $120 \mathrm{~V}$, and then into a $7.5 \%$ separation gel for $40 \mathrm{~min}$ at $200 \mathrm{~V}$. The proteins were then transferred on a membrane using a semidry method, for $45 \mathrm{~min}$ at $18 \mathrm{~V}$, at room temperature. Membranes were blocked for $1 \mathrm{~h}$ at room temperature with $5 \%$ nonfat milk in Tris-buffered saline-Tween (TBS-T) and incubated at $4^{\circ} \mathrm{C}$ overnight with 1:1,000 anti-MR $39 \mathrm{~N}$ and $1: 10,000$ anti- $\alpha$-tubulin (Sigma-Aldrich) for loading controls. The membranes were rinsed 3 times with TBS-T and incubated $1 \mathrm{~h}$ at room temperature with the DyLight Fluor secondary antibodies Rabbit 680 and Mouse 800 (1:15,000; Thermo Scientific). After 3 washes, the membranes were analyzed with Odyssey Fc (Li-cor Biosciences, Lincoln, NE, USA).

\section{Statistical analysis}

Experimental data are presented as the means \pm SEM. Statistical analyses were performed with Prism 5 software (GraphPad Software, La Jolla, CA, USA), with the nonparametric Mann Whitney $t$ test. Differences reaching $P<0.05$ were considered significant, as shown in detail in the figures.

\section{RESULTS}

\section{Pilot MR and H3K4me3 ChIP experiments}

To ensure appropriate experimental conditions before ChIP-seq analysis, we conducted pilot ChIP experiments. We used the HK-GFP-MR cells, a human renal cell line originating from the distal convoluted tubule that was originally stably transfected with an expression vector encoding for the fusion protein GFP-hMR (10). This cell line expresses both endogenous MR and GFP-MR fusion protein that can be immunoprecipitated with the anti-MR antibody 39N (11) (Supplemental Fig. S1 A, B). Moreover, as illustrated by a transactivation assay with a reporter plasmid encoding the luciferase gene placed under the control of a promoter containing 2 glucocorticoid response elements (GREs), or by the measurement of the aldosterone-induced expression of the SCNN1A gene, an endogenous and classic mineralocorticoid target gene, which encodes for $\alpha \mathrm{ENaC}$, the GFP-MR fusion protein is transcriptionally active (Supplemental Fig. S1C, D). After cross-linking, lysis, and sonication, HK-GFP-MR cell samples were immunoprecipitated with the anti-MR $39 \mathrm{~N}$, antiH3K4me3, or negative control IgG antibody. The trimethylation of histone $\left[{ }^{3} \mathrm{H}\right]$ lysine 4 is known to mark active transcription sites, enabling the recruitment of transcription factors. Isolated DNA was quantified by qPCR, with primers encompassing the well-documented MRE in the SCNN1A promoter ( -289 bp from the TSS) or a nearby control region $(+1068 \mathrm{bp}$ from the TSS). Aldosterone treatment induced a 15-fold increase in MR recruitment on the MRE, as compared to that induced by the vehicle control (Fig. 1). Moreover, MR enrichment was not observed in the control region after aldosterone exposure, clearly demonstrating that MR recruitment was locus specific. The strong H3K4me3 footprint enrichment on the MRE and control sequences indicated that the regions were transcriptionally active. Taken together, these findings clearly

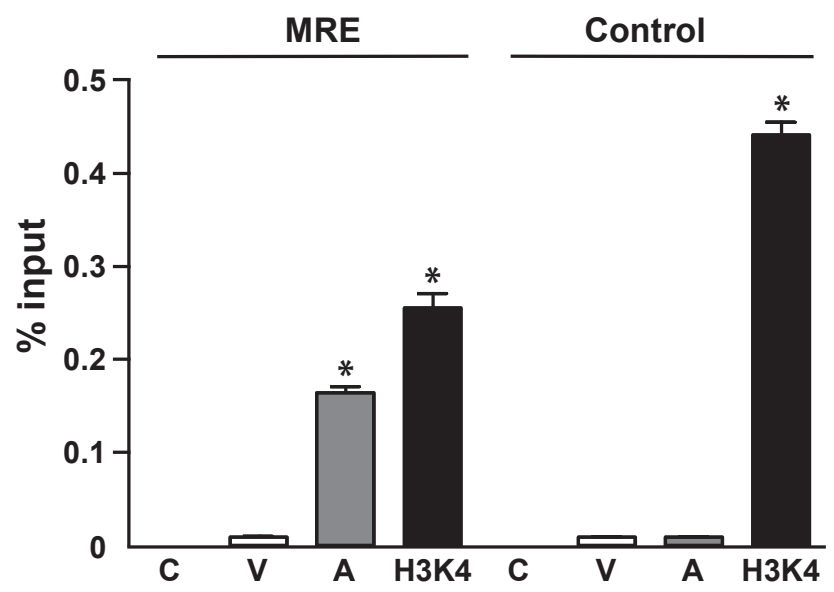

Figure 1. MR recruitment on promoter region of the $S C N N 1 A$ gene. ChIP assays on HK-GFP-MR cells, which were incubated with ethanol (V) or $100 \mathrm{nM}$ aldosterone (A) for $1 \mathrm{~h}$, fixed by paraformaldehyde, and lysed, and the chromatin was sheared. The samples were then immunoprecipitated with the anti-MR $39 \mathrm{~N}$ antibody, an antibody directed against the trimethylated lysine 4 of the $\left[{ }^{3} \mathrm{H}\right]$ histone (H3K4me3) or control rabbit IgG (C). After elution, the DNA was quantified by qPCR, using primers for the genomic fragment encompassing the MRE corresponding to the MBS located in the promoter region of $S C N N 1 A$ or a control negative region located at +1068 bp from the SCNN1A TSS (Control). Results are expressed as the percentage of input before immunoprecipitation (means \pm SEM). $* P<0.05$ vs. vehicle.

demonstrate that our experimental tools were suitable to identify genomic MR targets in human renal cells.

\section{MR ChIP-seq analysis}

To explore the whole-genome target genes of MR in HKGFP-MR cells, we performed a ChIP-seq analysis with $100 \mathrm{nM}$ aldosterone- or vehicle-treated cells. The bioinformatic analysis of sequencing data, using the MACS software, identified 974 peaks as putative MBSs. For each locus, MACS calculates a score that correlates directly to the probability that the number of reads in the aldosteronetreated condition is significantly higher than in the vehicle conditions [score $=-10 * \log (P)]$. A locus was regarded as a putative MBS when its score was higher than 50 (i.e., $P \geq 10^{-5}$ ). These peaks were annotated to flanking genes on the hg19 annotation of the human genome (GRCh37) by MACS, because the software had not been updated to include the latest version of the reference human genome GRCh38. Sequencing data were submitted to the Integrative Genomics Viewer (IGV; http://www.broadinstitute.org/igv/; Broad Institute) software, which aligns immunoprecipitated and sequenced fragments on hg19. The sequencing profiles of 2 MBSs, located on the SCNN1A gene promoter and on an intron of the ZBTB16 gene, showed, respectively, 1 and 2 peaks only in the aldosterone-treated condition (Fig. 2A). Adding that there is a peak in the H3K4me3immunoprecipitated sample, corresponding to an open reading frame, these peaks correspond to MBSs. It is important to note that the binding sites are found throughout the genome. Of the 974 identified MBSs, $84 \%$ were more 
A
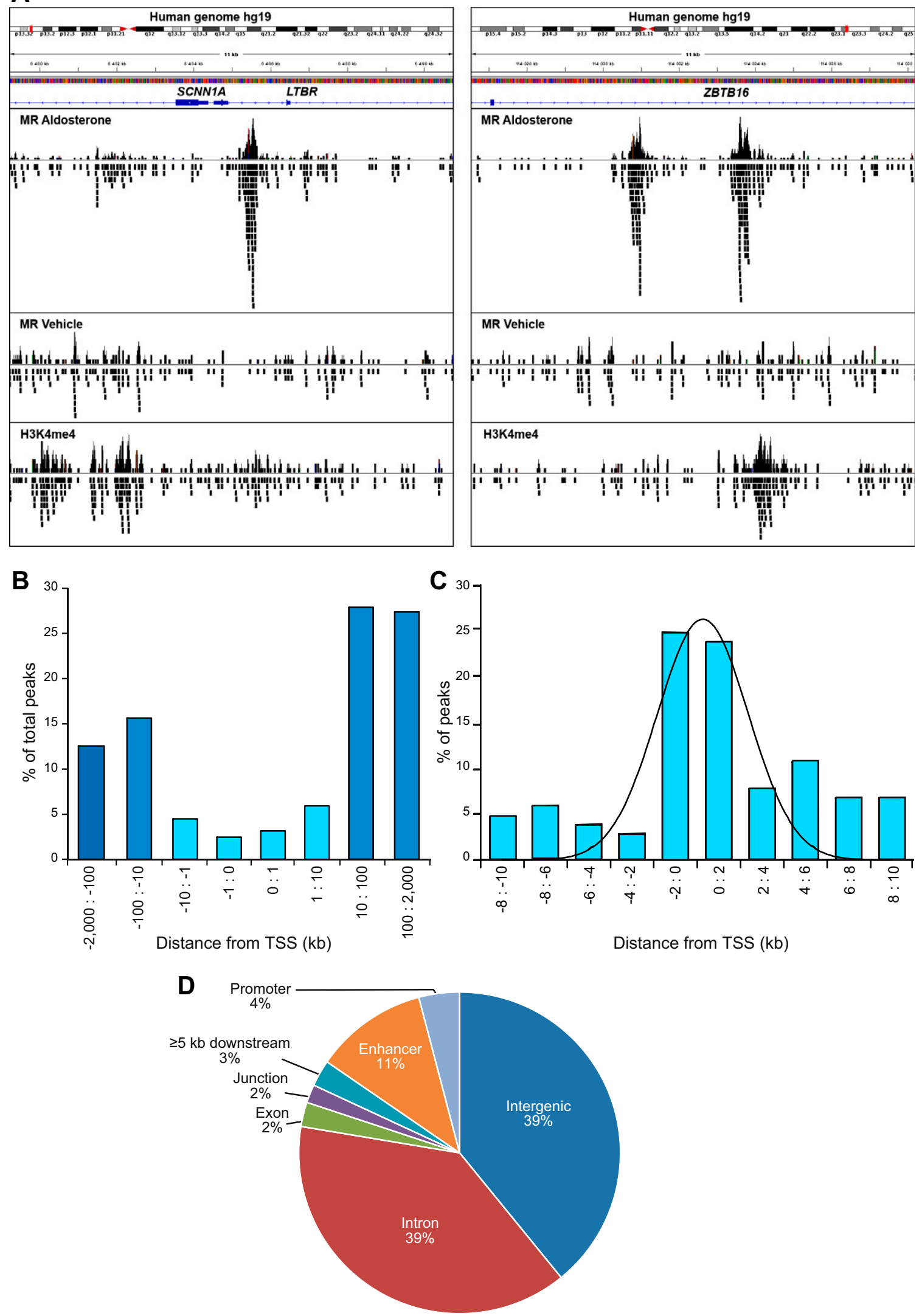

Figure 2. Distribution of ChIP-Seq reads across the human genome. A) Snapshot showing IGV software windows of the loci corresponding to the SCNN1A and ZBTB16 genes in the hg19 annotation of the human genome. ChIP-seq reads were aligned to the whole human sequence. For both SCNN1A and ZBTB16, the chromosome annotation (name, arm, and loci) are shown, with

(continued on next page) 
than $10 \mathrm{~kb}$ from the nearest TSS, with almost half of them more than $100 \mathrm{~kb}$ from the TSS (Fig. 2B). The remaining $16 \%$ present a Gaussian distribution centered on the TSS position (Fig. 2C). Among the 974 identified MBSs, almost half were intragenic: $39 \%$ within introns, $2 \%$ in exon regions, and $2 \%$ within exon-intron junctions (Fig. $2 D$ ). For the others, $39 \%$ were intergenic and between 30 and $2000 \mathrm{~kb}$ from the TSS, $11 \%$ within enhancers (2-30 kb from the TSS), $4 \%$ within promoter regions $(>2 \mathrm{~kb}$ from the TSS), and $3 \%$ more than $5 \mathrm{~kb}$ downstream of the TSS.

\section{MR binding motif analysis and definition of MRE}

To evaluate the consensus motif on which the MR binds, we used FIMO software on our results of ChIP-seq analysis. We found 251 identified palindromic and half-MREs among the MBSs. More precisely, only 7.4\% (70/974 peaks) of the MBSs exhibited a palindromic MRE that was close $(P<0.0001)$ to the consensus classic palindromic GRE, a 15 bp motif composed of 2 inverted hexanucleotides (half-sites) separated by $3 \mathrm{bp}$, commonly recognized by MR, GR, androgen receptor (AR), and progesterone receptor (PR) (AGAACAnnnTGTTCT; Fig. 3A; Table 1). To our surprise, only $1 \mathrm{MBS}$, related to the FKBP5 gene, exhibited 2 well-conserved palindromic MREs. It is interesting that palindromic MRE distribution throughout the whole genome was similar to that of the MBSs, in that $94 \%$ of them were located more than $10 \mathrm{~kb}$ away from the nearest TSS. Moreover, among all identified MREs, 58.6\% (147) consisted of single conserved half-MREs (AGAACA; $120 / 147 ; 81 \%)$ or more $(2,3$, or 4 -half sites). Some MBSs $(16 / 251 ; 6.3 \%)$ even exhibited a combination of a palindromic and at least 1 half-MRE (Table 1 . A detailed analysis of the identified MRE on high-, medium-, and low-score MBSs was performed with the Jaspar software (18). In each group, base variability was analyzed with the Weblogo and compared with the MRE (Fig. 3B). The highest scores $(>200)$ were associated with an MRE motif close to the consensus response element, with a notable variability on bases 3 and 13 (AGxACAnnnTGTxCT). Peak scores $>80$ were associated with relatively wellconserved MRE motifs, keeping a palindromic dyad in which the bases G2, A4, C5, and A6 (and T10, G11, T12, and C14 by symmetry) seemed to be the most important for MR binding and occupancy (xGxACAnnnTGTxCx). In contrast, peaks with the lowest scores $(\sim 50)$ were often associated with very degenerated MREs in which the bases C5 and G11 remained essential. The recently solved crystal structure of a dimer of the MR DNA-binding domain (DBD), bound to the palindromic sequence AGAACAnnnTGTTCT, revealed the sequence-specific contacts between the MR DBD and the DNA bases (20). Consistent with our definition of a consensus MRE and, as depicted in Fig. $3 C, D$, on 1 half-site, Lys $^{624}$ contacts guanine $^{2}$ (fG2) from the forward oligonucleotide and $\mathrm{Val}^{625}$ and $\mathrm{Arg}^{629}$ contact thymine ${ }^{12}$ (rT12) and guanine ${ }^{11}$ (rG11) from the reverse oligonucleotide, respectively. In sharp contrast, the bases at positions 1,3 , and 6 (numbered in the forward oligonucleotide) do not establish any contact with the side chains of the MR DBD (Fig. $3 C, D$ ).

To determine the occurrence of other motifs in the MBSs, we used the MEME suite software. Four motifs were found to correspond to DNA binding recognition sites of 4 family members of transcription factors, including early growth response protein 1 (EGR1), forkhead box (FOX), paired box protein 5 (PAX5), and activated protein 1 (AP-1) (Fig. 4A). Their number and percentage are reported in a Venn diagram (Fig. 4B). Only 4.5\% (54/974) displayed a combination of an MRE with another motif, suggesting potential cooperation between these transcription factors and MR. Moreover, most of the MBSs (723 peaks; $74.2 \%$ ) did not exhibit any MRE, indicating that MR did not directly bind to DNA but rather may have interacted with other transcription factors within multimeric transcriptional complexes that remain to be further characterized.

\section{Validation of genomic MBSs}

To confirm the results of ChIP-seq, we focused on the first 15 peaks with the highest scores (Table 2). They were associated with 13 genes. Two of them, ZBTB16 and FKBP5, contained 2 MBSs. All identified genes were scattered throughout the genome. Peaks are located upstream, downstream, or within a gene, or in the intergenic region (94-223 kb from their TSSs). Four of the genes have already been associated with mineralocorticoid signaling: zinc finger and BTB domain containing 16 (ZBTB1G), FK506 binding protein (FKBP5), SCNN1A, and period circadian clock 1 (PER1). So far, the 9 others have not been identified as playing any significant role in renal mineralocorticoid signaling: endoplasmic reticulum-Golgi intermediate compartment 1 (ERGIC1); family with sequence similarity 65 , member $\mathrm{B}(F A M 65 B)$; long intergenic non-protein coding RNA 963 (LINC00963); nuclear factor of activated T-cells, cytoplasmic, calcineurin-dependent 2 (NFATC2); nuclear factor of kappa light polypeptide gene enhancer in B-cells inhibitor, alpha (NFKBIA); protein tyrosine phosphatase, non-receptor type 1 (PTPN1); serpin peptidase inhibitor, clade $\mathrm{E}$ (nexin, plasminogen activator inhibitor type 1); member 1 (SERPINE1); tumor protein p63 regulated 1 (TPRG1); and zinc finger, MYND-type containing 8 (ZMYND8). It was thus essential to validate ChIP-seq data analysis. We first evaluated the aldosteroneinduced recruitment of MR on the sites corresponding to these 13 genes by performing additional ChIP experiments on HK-GFP-MR cells. To quantify DNA fragment enrichment after MR immunoprecipitation, we performed realtime PCR with specific genomic primer pairs surrounding the identified MREs on each site (Supplemental Table S1). The results are expressed as the percentage of input, according to the formula in which the $C_{\mathrm{t}}$ value of

a focus on the gene with its intron and exon organization and the aligned ChIP-seq reads for the vehicle- or aldosterone-treated samples immunoprecipitated by the anti-MR 39N antibody and the anti-H3K4me3-immunoprecipitated sample. Distribution of the reads by their distance from $(B)$ the TSS and $(C)$ a zoom on the zone at less than $10 \mathrm{~kb}$ from the TSS. $D$ ) Distribution of the reads according to locus type. 

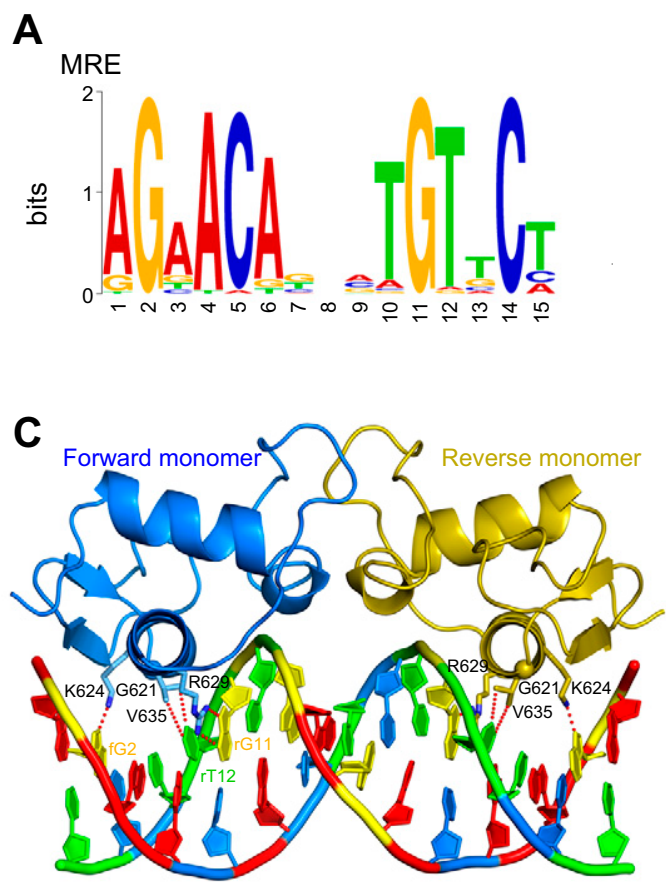

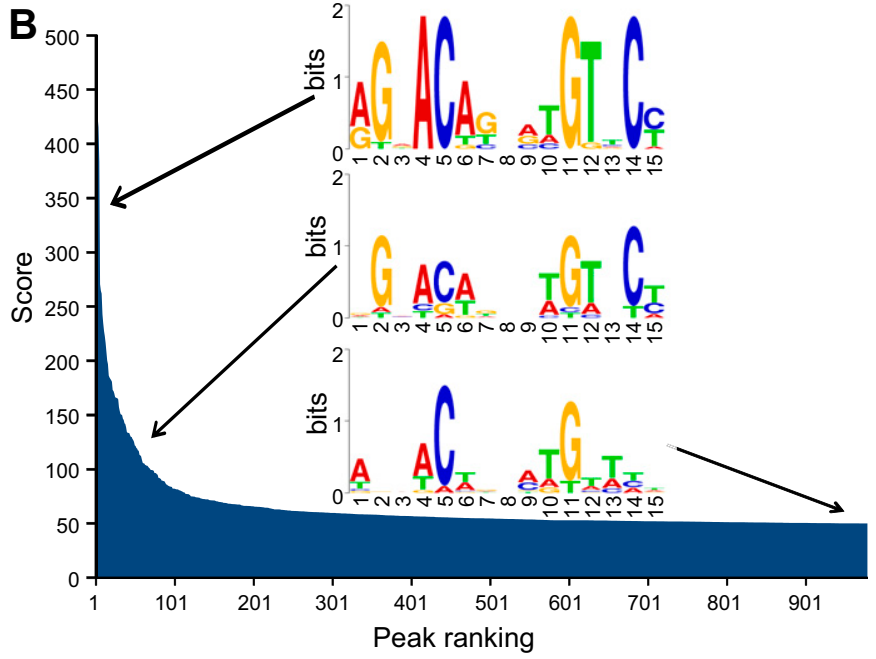

D

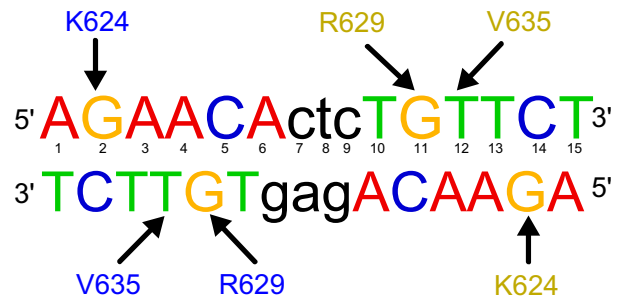

Figure 3. Characterization of the MRE. A) Identification of an MRE and a half-MRE within the MBS by FIMO software, and their distribution alone or in combination (Table 1). B) Distribution profile of the scores [equal to $-10 \log (P)$ ] allotted by the MACS software to the identified MBSs. MREs were identified with Jaspar software on MBSs, according to 3 grades: high ( $\leq 200$ ), intermediate $(\geq 80)$, and low $(\sim 50)$. C) The crystal structure of a dimer of MR DBD bound to the canonical MRE (Protein Database identification number: 4TNT) (20). Forward (blue) and reverse (gold) MR DBD monomers are depicted. Only critical residues of the DBD interacting helix are shown with the nitrogen atoms in blue. The DBD is schematically represented with the nucleotides in red, blue, yellow, and green for the adenine, cytosine, guanine, and thymine bases, respectively. Dashed lines: interactions between the amino acids of the MR DBD and the DNA bases. The figure was generated using Open PyMol, ver. 0.93. D) Schematic representation of the key contacts between the residues from the DNA interacting helix of the MR DBD dimer with the nucleotide of the MRE. Bases are numbered from the $5^{\prime}$ to the $3^{\prime}$ end. Arrows: specific contacts between the MR residues and the DNA bases.

each immunoprecipitated sample was normalized to its input $C_{\mathrm{t}}$ value. Of interest, a significant increase in MR enrichment $(P<0.05)$ was detected for all sites when the aldosterone-treated conditions were compared to the vehicle-treated conditions (Fig. 5). These results validate aldosterone-induced MR occupancy on all 13 binding sites identified by ChIP-seq (Table 2). We also showed that MR recruitment was significantly enhanced by aldosterone stimulation for PIK3R1, a genomic target that lacks classic MREs (Supplemental Fig. S2), a finding that validates the discovery of genomic MR targets by ChIP-seq analysis.

TABLE 1. Distribution of palindromic MREs and half-MREs, alone or in combination

\begin{tabular}{lrrrrr}
\hline \hline & & \multicolumn{4}{c}{ Sites $(n)$} \\
\cline { 3 - 6 } & Total & \multicolumn{1}{c}{1} & 2 & 3 & 4 \\
\hline Palindromic MRE & 70 & 69 & 1 & - & - \\
Half-MRE & 147 & 120 & 22 & 4 & 1 \\
Combination & 16 & 15 & 1 & - & - \\
\hline
\end{tabular}

The MRE, as identified by FIMO software, is shown in Fig. $3 \mathrm{~A}$.

\section{Correlation between genomic MR occupancy and transcriptional activation}

To clarify whether the enhancement of MR binding on gene regulatory sequences leads to a subsequent transcriptional regulation of the corresponding genes, we determined mRNA levels of the corresponding gene after aldosterone treatment of human renal cells. Given that MR-induced gene transactivation is a dynamic process that depends not only on the complex interaction between molecular partners but also on the stability of newly synthesized nascent transcripts, we performed a time-dependent stimulation of HK-GFPMR cells with $10 \mathrm{nM}$ aldosterone. Total RNAs were extracted, reverse transcribed, and quantified by realtime PCR with specific primer pairs (Supplemental Table S1). Data analysis enabled us to classify genes into 4 categories, according to their mineralocorticoid responsiveness, consisting of early, intermediate and late target genes or nonregulated genes (Fig. 6 and Table 3). Among those, steady-state mRNA levels of the PER1 gene significantly increased $(P<0.05)$ as early as $30 \mathrm{~min}$ after aldosterone stimulation, in comparison to the vehicle 
A

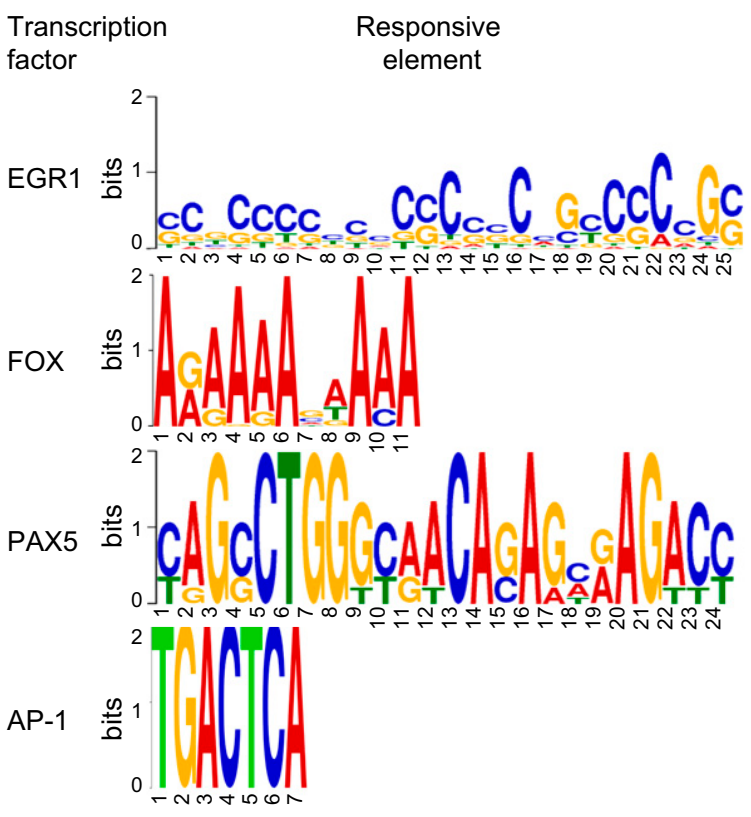

B

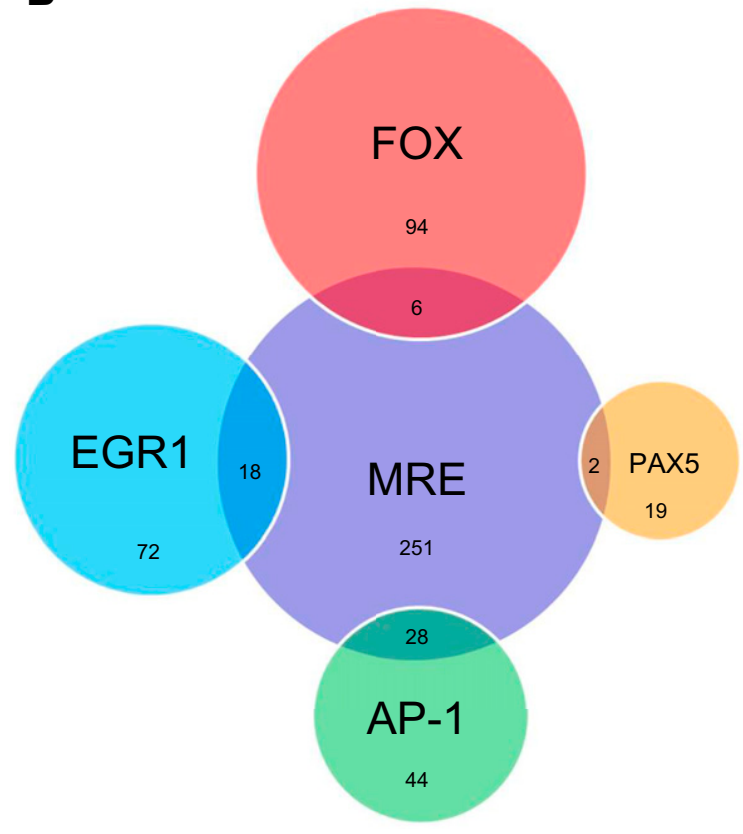

Figure 4. Identification of alternative response elements. A) Identification of other transcription factor response elements by the MEME suite web server and $(B)$ association with a palindromic MRE or another half-MRE.

condition. Accordingly, PER1 a major actor in the endogenous intracellular gene clock, was classified as an early target gene of MR. Likewise, mRNA levels of FKBP5, SCNN1A, SERPINE1, NFATC2, NFKBIA, and FAM65Bwere significantly increased after $4 \mathrm{~h}$ of aldosterone treatment and thus were classified as intermediate MR-regulated target genes. Finally, PTPN1, TPRG1, ERGIC1, ZBTB16, and $Z M Y N D 8$ were considered to be late regulated genes, because their expression levels were significantly increased after $24 \mathrm{~h}$ of treatment $(P<0.05)$. With respect to $L I N C 00963$, its expression was not significantly modified after aldosterone exposure. Thus, although MR was found to bind to a sequence located in the intergenic region at
$112,000 \mathrm{bp}$ from the TSS of the nearest gene (i.e., LINC00963), it is very likely that MR occupancy on this specific motif affects transcription of another unidentified gene located within a region $>100 \mathrm{~kb}$ downstream or upstream.

\section{Composition of MR-mediated preinitiation complexes}

MR recruitment on $\mathrm{MRE}$ in response to aldosterone treatment is one of the first and most critical steps in the ongoing transcription process of target genes. Recruitment of the preinitiation complex is an extremely

TABLE 2. Characteristics of the first 15 genomic MR binding motifs

\begin{tabular}{|c|c|c|c|c|c|c|}
\hline Gene & Chromosome & Localization & Distance TSS & Score & Locus type & MR response element \\
\hline & & & & & Consensus GRE & AGAACAnnnTGTTCT \\
\hline \multirow[t]{2}{*}{ ZBTB16 } & 11 & $114,033,640$ & $+102,353$ & 497 & Intron & $\overline{\text { AGAACA }}$ сас $\overline{\text { TGTACC }}$ \\
\hline & & $114,030,889$ & $+99,602$ & 415 & Intron & GGTACAg ta \\
\hline \multirow[t]{2}{*}{ FKBP5 } & 6 & $35,695,858$ & +502 & 427 & Intron & 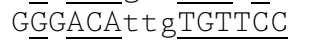 \\
\hline & & $35,699,815$ & $-5,043$ & 264 & Intron & 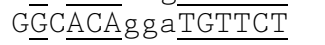 \\
\hline SCNN1A & 12 & $6,485,465$ & $-1,075$ & 424 & Promoter & A $\overline{G A A C A} g a a$ TGTCCT \\
\hline PER1 & 17 & $8,057,797$ & $-2,044$ & 383 & Enhancer & $\overline{\text { AGAACA }}$ tga $\overline{\text { TGTTCC }}$ \\
\hline NFKBIA & 14 & $35,873,155$ & +805 & 271 & Intron & $\overline{\text { AGTACAggg } \overline{C G T T C} C}$ \\
\hline TPRG1 & 3 & $188,665,933$ & $-223,829$ & 262 & Intergenic & $\overline{\mathrm{AG}} \mathrm{GACT}$ g taA $\overline{\mathrm{GGCC}} \mathrm{C}$ \\
\hline PTPN1 & 20 & $49,032,357$ & $-94,533$ & 243 & Intergenic & GGGACAtarTGTGCT \\
\hline NFATC2 & 20 & $49,948,239$ & $+211,019$ & 235 & Intergenic & A $\overline{G A C G}$ g c g $\bar{C} G \overline{T C C T}$ \\
\hline$F A M 65 B$ & 6 & $25,006,801$ & $-95,606$ & 227 & Intergenic & $\overline{\mathrm{AGAAC}}$ g gagA $\overline{\mathrm{GTTC}} \overline{\mathrm{CC}}$ \\
\hline ERGIC1 & 5 & $172,296,284$ & $+35,062$ & 223 & Intron & AGGACAgc gTGTGCT \\
\hline LINC00963 & 9 & $132,195,193$ & $+111,899$ & 216 & Intergenic & GTAACA сас TGTTCC \\
\hline$Z M Y N D 8$ & 20 & $45,963,033$ & $+22,441$ & 200 & Intron & AGTACAg a cA $\overline{\text { ATTCC }}$ \\
\hline \multirow[t]{2}{*}{ SERPINE1 } & 7 & $100,755,724$ & $-14,654$ & 197 & Enhancer & AGGACTtcaTGTTCT \\
\hline & & & & & Consensus MRE & $\overline{\mathrm{AG}} \mathrm{n} \overline{\mathrm{ACA} A n n n \mathrm{TGTn} \mathrm{C} C} / \mathrm{T}$ \\
\hline
\end{tabular}

The MR-binding motifs identified by ChIP-seq are summarized. The sequence localization is according to the hg19 annotation of the human genome (GRCh37). Proposed MRE sequences are identified by Jaspar. Nucleotides in uppercase letters correspond to the nucleotide bases of the 2 half-sites and those underlined correspond to the ones that are identical to the corresponding nucleotide of the canonical consensus GRE. 

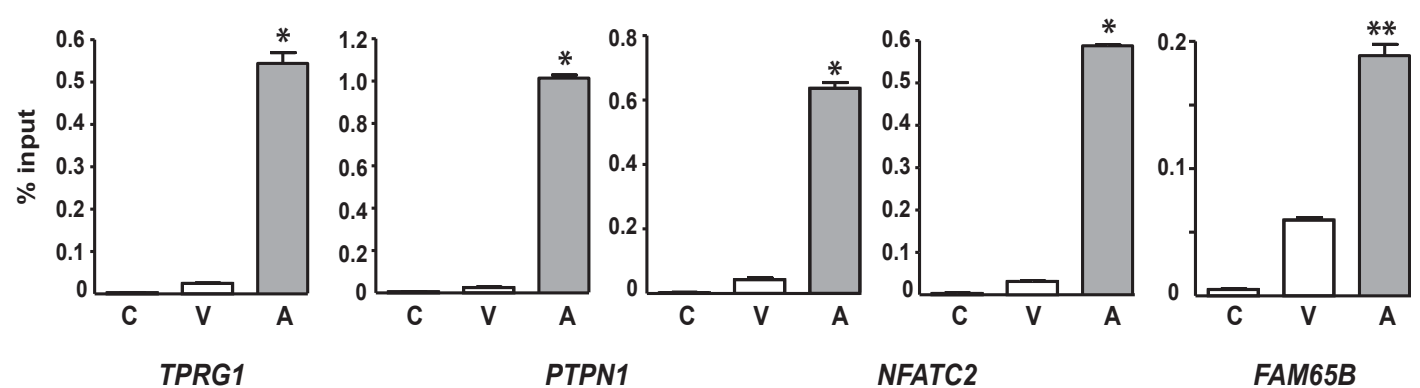

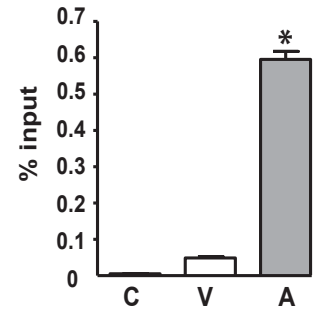

ERGIC1

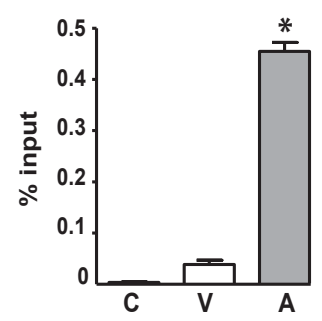

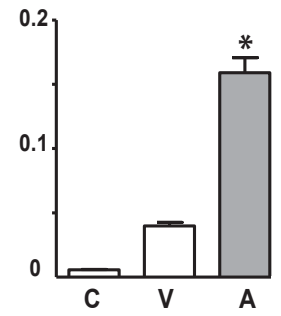

LINC00963

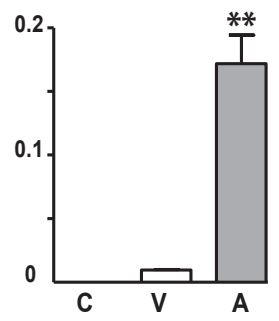

NFATC2

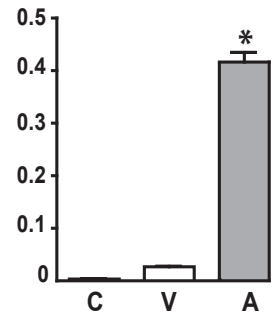

ZMYND8

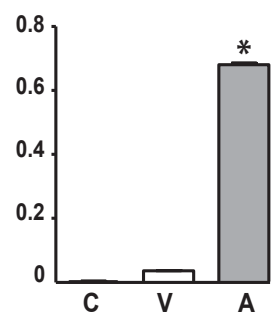

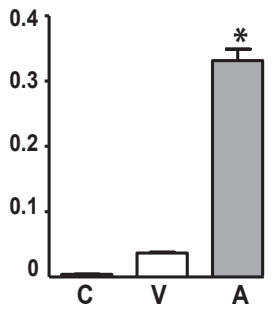

SERPINE1

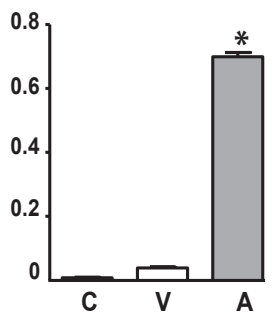

Figure 5. MR recruitment on regulatory regions of identified target genes. HK-GFP-MR cells, treated for $1 \mathrm{~h}$ with vehicle (V) or $100 \mathrm{nM}$ aldosterone (A), were fixed by paraformaldehyde and lysed. After they were sheared, chromatin extracts were immunoprecipitated by the anti-MR 39N antibody or by the control IgG antibody (C). Eluted DNAs were quantified by real-time qPCR, with primer pairs encompassing MBSs (Supplemental Table S1). Results are expressed as percentage of input, and are means \pm SEM of 3 independent experiments performed in triplicate. $* P<0.05$ or $* * P<0.01$ vs. the vehicle condition.

intricate mechanism, in which hundreds of molecular partners are associated in a sequential, cyclic, combinatorial manner (21). Combining analysis of MR-binding, MR coactivator, and RNA polymerase II (RNA pol II) occupancy aided us in evaluating the functional consequences of aldosterone treatment on preinitiation complex assembly in the context of ongoing transcription associated with modifications of local chromatin landscape and remodeling and histone posttranscriptional signatures. As a first approach, we sought to determine the ability of MR to promote the recruitment of the SRC1 coactivator and of RNA Pol II. New ChIP experiments were performed on chromatin extracts from HK-GFP-MR cells treated for $1 \mathrm{~h}$ with $100 \mathrm{nM}$ aldosterone or vehicle or 1 $\mu \mathrm{M}$ of the mineralocorticoid antagonist, spironolactone. ChIP was subsequently performed with anti-MR 39N, antiSRC1, or anti-RNA Pol II antibodies. MR, SRC1, and RNA pol II occupancies were evaluated on the SCNN1A promoter by quantitative genomic PCR. As illustrated in Fig. 7, aldosterone treatment led to significant recruitment of MR but also of SRC1 and RNA pol II, as compared with the vehicle-treated condition $(P<0.05)$. Of interest, under similar experimental conditions, although the MR antagonist promoted both MR and SRC1 recruitment on the
SCNN1A promoter $(P<0.05)$, spironolactone did not induce substantial RNA pol II recruitment, which may account for the repression of transcription initiation in response to this antagonist.

\section{DISCUSSION}

In the present study, we report the first whole-genome identification and characterization of specific binding sites for the human MR on the chromatin of the human renal cell. The availability of a human renal MR-overexpressing cell type (HK-GFP-MR) and a specific and suitable anti-MR antibody (39N) enabled us to perform a ChIP-seq analysis for MR. This approach aided us in identifying 974 aldosteronespecific MBSs, only 7\% of which contained a classic palindromic MRE. The aldosterone-induced recruitment of MR was further validated onto the first 15 highest scored peaks together, which correlated with the time-dependent, mineralocorticoid-specific activation of the corresponding gene transcription.

Identifying genome-wide MR targets is of major importance in providing a better understanding of renal mineralocorticoid signaling. The bioinformatic analyses of our 
A Unregulated gene

LINC00963

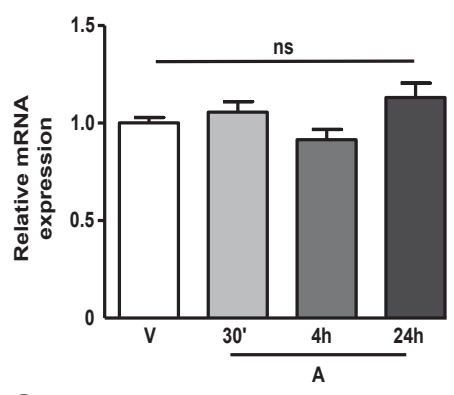

C Intermediary target genes

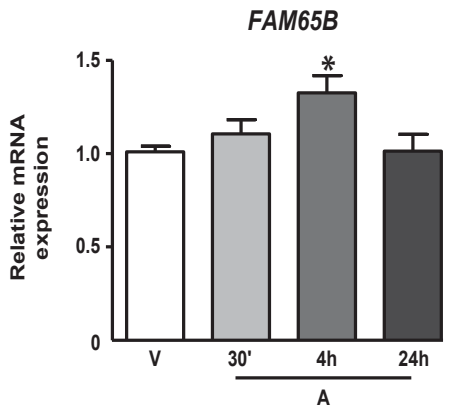

NFKBIA

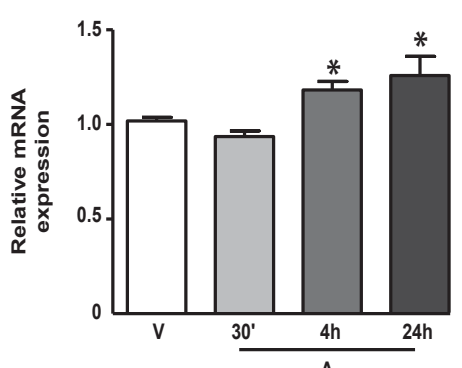

D Late target genes
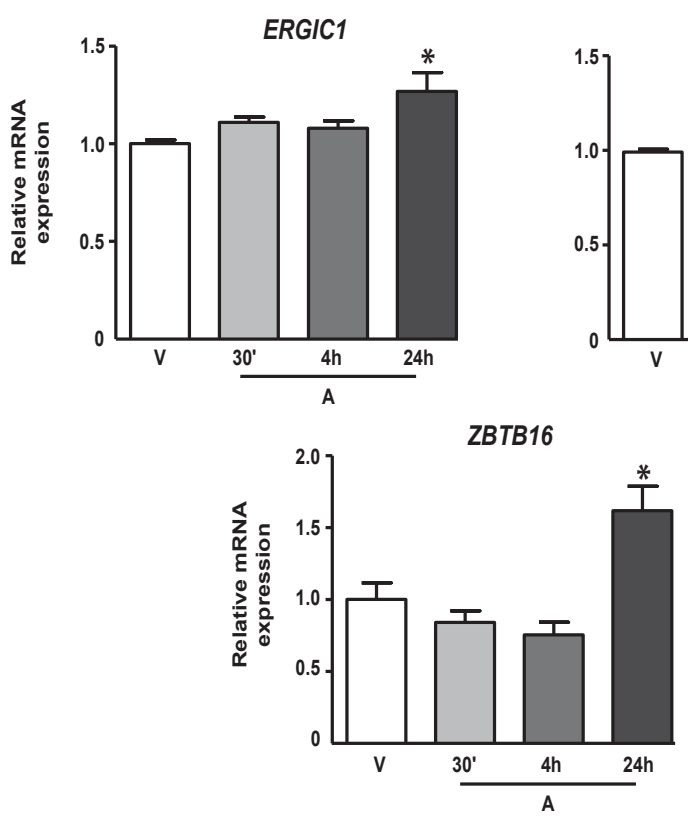

B Early target gene

PER1

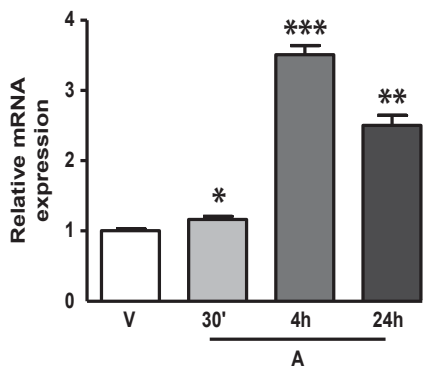

FKBP5

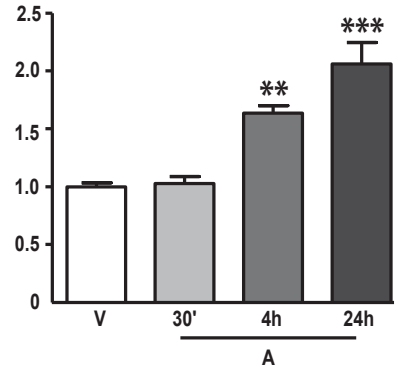

SCNN1A
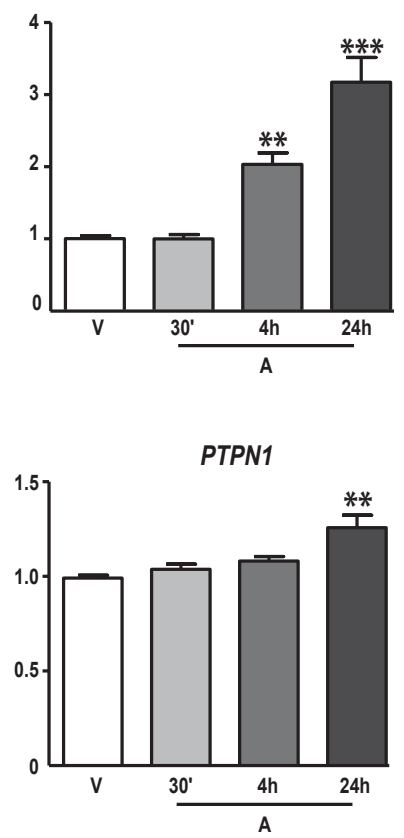

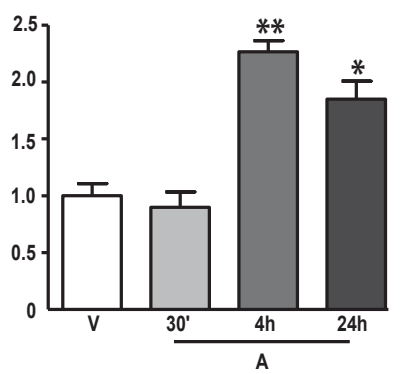

TPRG1

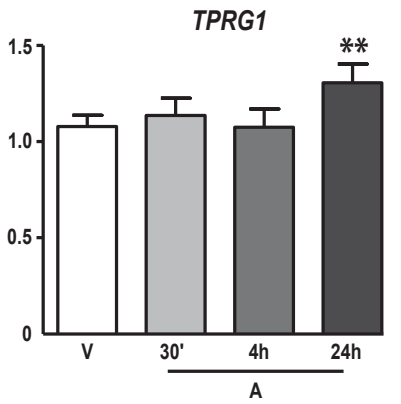

ZMYND8

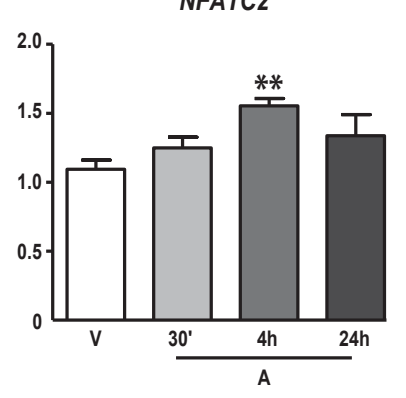

SERPINE1

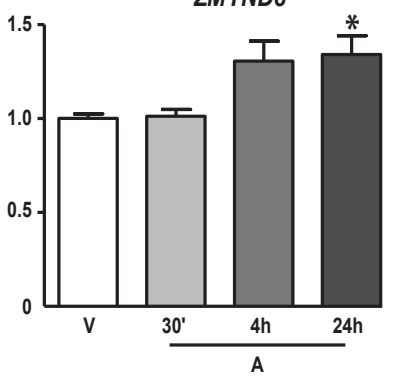

Figure 6. Aldosterone-induced transcriptional activation of identified MR target genes. HK-GFP-MR cells were treated at 3 time points (from $30 \mathrm{~min}$ to $24 \mathrm{~h}$ ) with vehicle (V) or $10 \mathrm{nM}$ aldosterone (A) and lysed, and total RNAs were isolated. After RT, the (continued on next page) 

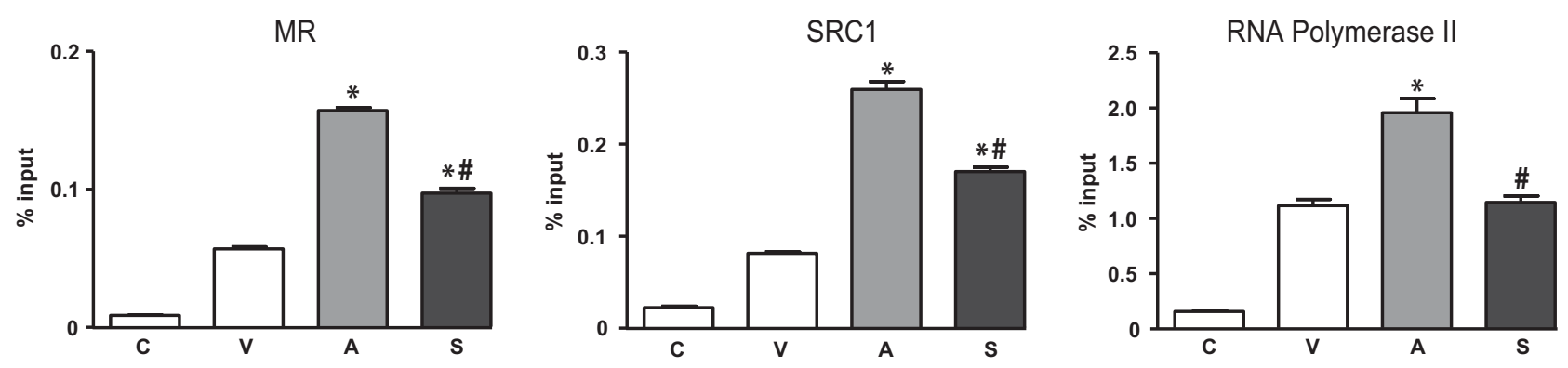

Figure 7. Ligand specificity of MR recruitment together with coactivator SRC1 and RNA pol II occupancy on the SCNN1A gene promoter sequence. HK-GFP-MR cells, treated for $1 \mathrm{~h}$ with vehicle (V), $100 \mathrm{nM}$ aldosterone (A), or $1 \mu \mathrm{M}$ spironolactone (S), were fixed and lysed. Chromatin extracts were sheared before being immunoprecipitated by a negative control antibody (C) or antibodies against MR, SRC1, or RNA pol II. Eluted and purified DNA fragments were quantified by real-time qPCR, using primers amplifying the genomic fragment of the SCNN1A promoter (Supplementary Table S1). Data are expressed as the percentage of input, and are means \pm SEM of 3 independent experiments performed in triplicate. ${ }^{*}{ }^{*} P<0.05$ vs. vehicle and aldosterone, respectively.

ChIP-seq data, by comparing reads in aldosterone- $v$. vehicle-stimulated conditions, enabled us to identify approximately 1000 MR binding regions. We focused our attention and performed subsequent characterizations on the first 15 identified MBSs, related to 13 different genes spanning the whole genome and having the highest score $(\geq 200)$ of aldosterone-induced MR recruitment. The specific MR recruitment was further confirmed by additional ChIP qPCR experiments under $1 \mathrm{~h}$ aldosterone vs. vehicle exposure, indicating that the ChIP-seq approach was a robust method for identifying the genome-wide mapping of MR target genes. It is notable that the 6 highest scored MBSs were associated with 4 target genes, already defined as important players in the renal MR signaling pathway: SCNN1A, FKBP5, ZBTB16, and PER1. SCNN1A encodes the $\alpha$-subunit of the well-characterized epithelial sodium channel $(\alpha \mathrm{ENaC})$, which plays a major role in transepithelial sodium reabsorption (22). FKBP5 encodes an HSP90 cochaperone protein that participates in the stability of the cytosolic MR (23). ZBTB16 encodes a transcriptional repressor of the $\beta$ and $\gamma$ subunits of ENaC (24), whereas PER1, belonging to the circadian clock gene family, is known to regulate the rhythmicity of renal sodium reabsorption through transcriptional activation of several sodium transporters, including ENaC (25-27). The 9 other genes (NFATC2, FAM65B, NFKBIA, TPRG1, ERGIC1, ZMYND8, PTPN1, SERPINE1, and LINC00963) have not been reported so far to play any functional or mechanistic role in human renal mineralocorticoid signaling. Of note, such MBSs have not been identified in the recently published ChIP-seq performed on a murine convoluted collecting duct (CCD) cell model expressing a 3xFLAG-tagged human MR (28). Despite the implication of these genes in various biologic processes, such as cell differentiation [FAM65B (29)], mobility [NFATC2 (30)], and antiapoptotic actions [TPRG1 (31)], their function in sodium-transporting polarized epithelial cells remains to be demonstrated.
We were able to show that MR binding to genomic sequences was associated with transcriptional activation of aldosterone-responsive genes whose expression was differentially stimulated in a time-dependent manner. The 13 target genes were classified into 3 categories of mineralocorticoid-responsive genes, according to their early $(<1 \mathrm{~h})$ (PER1), intermediate $(4 \mathrm{~h})($ FAM 65B, FKBP5, NFATC2, NFKBIA, SCNN1A, and SERPINE1), or late (24 h) (ERGIC1, PTPN1, TPRG1, ZBTB16, and ZMYND8) stimulation by aldosterone exposure. The time-dependent responsiveness is one of the main features of the transcriptional gene activation, consistent with the short- or long-term effects of hormonal signaling, and is well supported by the transcriptional clock defined as the cyclic, sequential, and combinatorial assembly of a transcriptionally productive complex onto a regulatory sequence (21). It has to be pointed out that, among the 13 investigated genes, LINC00963 was unexpectedly not regulated by MR, even though a high-score peak was identified in a desert region, located $111 \mathrm{~kb}$ downstream from the nearest TSS of this gene, and the highly significant aldosterone-induced MR recruitment was validated on this MBS by ChIP qPCR. The massive MR recruitment at this site unambiguously demonstrated the validity of this MBS but clearly indicated that it is likely to be involved in the transcriptional regulation of another target gene, very likely located far away in the genome, as suggested by Hou and Corces (32). Even though such a regulated gene is presently unknown, theuse of alternate methodology, such as the chromatin interaction analysis by the paired-end tag sequencing approach (ChIA-PET) (33) may actually facilitate its identification.

The first 4 genes, displaying the highest MBS score (ZBTB16, FKBP5, SCNN1A, and PER1), have been defined as MR target genes. As opposed to the results of Ueda $\mathrm{et} \mathrm{al}$. (28), our ChIP-seq data unexpectedly did not identify any MBSs on the SGK1, another classic and well-characterized

cDNAs were quantified by real-time qPCR (primer pairs in Supplemental Table S2). Relative gene expression values were normalized to that of $18 \mathrm{~S}$ rRNA and expressed as fold induction compared with vehicle, arbitrarily set at 1 . Data are means \pm SEM of 3 independent experiments performed in duplicate. NS, no significant difference; $* P<0.05, * * P<0.01, * * * P<0.001$ vs. vehicle. 
TABLE 3. Summarized relationship between genomic MR targets identified by ChIP-Seq and transcriptional activation of novel aldosterone-regulated genes

\begin{tabular}{|c|c|c|c|c|}
\hline Gene & Locus type & Distance from TSS & $\begin{array}{c}\text { Recruitment } \\
\text { (fold enrichment) }\end{array}$ & $\begin{array}{l}\text { Transactivation } \\
\text { (fold induction) }\end{array}$ \\
\hline \multicolumn{5}{|l|}{ Early } \\
\hline PER1 & Enhancer & $-2,044$ & 19 & 3.5 \\
\hline \multicolumn{5}{|l|}{ Intermediary } \\
\hline FAM65B & Intergenic & $-95,606$ & 9 & 1.3 \\
\hline \multirow[t]{2}{*}{$F K B P 5$} & Intron & +502 & 39 & 1.6 \\
\hline & Intron & $-5,043$ & ND & \\
\hline NFATC2 & Intergenic & $+211,019$ & 15 & 1.6 \\
\hline NFKBIA & Intron & +805 & 3 & 1.2 \\
\hline$S C N N 1 A$ & Promoter & $-1,075$ & 15 & 2.1 \\
\hline SERPINE1 & Enhancer & $-14,654$ & 18 & 2.2 \\
\hline \multicolumn{5}{|l|}{ Late } \\
\hline ERGIC1 & Intron & $+35,062$ & 12 & 1.2 \\
\hline PTPN1 & Intergenic & $-94,533$ & 4 & 1.3 \\
\hline TPRG1 & Intergenic & $-223,829$ & 12 & 1.3 \\
\hline \multirow[t]{2}{*}{ ZBTB16 } & Intron & $+102,353$ & 22 & 1.6 \\
\hline & Intron & $+99,602$ & ND & \\
\hline ZMYND8 & Intron & $+22,441$ & 18 & 1.4 \\
\hline \multicolumn{5}{|l|}{ Unregulated } \\
\hline LINC00963 & Intergenic & $+111,899$ & 18 & Unregulated \\
\hline
\end{tabular}

Recruitment is the fold induction of MR occupancy expressed as a percentage of the input ratio of the aldosterone $v s$. the vehicle sample. Transactivation is the aldosterone-induced transcriptional activation of the corresponding gene expressed as the relative gene expression ratio of the aldosterone vs. the vehicle sample.

renal mineralocorticoid target (34). However, we were able to demonstrate significant MR recruitment onto the well-characterized SGK1-containing MBS by ChIP-qPCR analysis and to show that $1 \mathrm{~h}$ aldosterone exposure stimulated SGK1 expression in HK-GFP-MR cells, as measured by RT-qPCR (data not shown). Such discrepant results clearly indicate that the ChIP-seq approach has its own intrinsic limitations, depending on the experimental conditions used, and strongly suggest the imperative for developing alternative and confirmatory methods in the search of genomic MR-specific binding sequences and the functional consequences of such MR recruitment. Identification and characterization of transcription factor binding sites are obviously highly dependent on the experimental conditions-notably, the cell type, the antibody and its recognized epitope, and the endogenous nature of the studied DNA-binding protein.

Studies have already established a canonical HRE for the oxo-steroid receptors, referred as to GREs: AGAACAnnnTGTTCT. Among the 974 MBSs identified in the present study, one quarter contained a well-conserved canonical MRE or a half-MRE (70 palindromic and 147 halfMRE motifs). However, sequence degeneration markedly increased as the peak scoring of the MBS decreased, the main conserved bases in the half-sites being xGxACx.

With respect to the MR binding motifs identified by our ChIP-seq analysis, it was somehow surprising to find that only $\sim 15 \%$ of the MREs were located $10 \mathrm{~kb}$ from the TSS. This finding was in accordance with what was reported for genomic binding sites of PRs (35) and glucocorticoid receptors (GRs) (36). Unlike MR, most AR binding sites were adjacent to their target gene TSSs $(37,38)$. Most MBSs are located outside the $10 \mathrm{~kb}$ distance from the TSS, including 9 of the 13 genes we investigated. These findings have led us to propose that the MR may directly bind a consensus MRE in a very restricted number of promoter regions (4\%) (either 1 or 2 MRE or half-sites), whereas it more frequently interacts with a large number of other genomic motifs including not only the MRE but also the response elements of other transcriptional factors with which it may interact through a tethering mechanism, as previously described for other steroid receptors (39). This hypothesis is further supported by our MEME suite motif analysis that highlighted the occurrence of 4 other binding sites, notably the EGR1, FOX, PAX5, and AP-1 recognition sites, suggesting cooperative interplay between specific transcription factors and MR, even far away from the TSS. Identification of such alternative MR binding genomic motifs, sometimes in association with a full or half-MRE, is consistent with the combinatory and dynamic assembly of the preinitiation complex (40). This transcriptional clock described by Gannon's group (21) relied on results obtained by ChIP-qPCR, in which ER $\alpha$ binding to DNA directs ordered recruitment of coactivators, such as SRC1, sequentially followed by RNA pol II assembly, finally leading to competent and productive transcriptional complexes. Experiments investigating MR recruitment onto the $S C N N 1 A$ promoter demonstrated a coordinate recruitment of SRC1 and of RNA pol II with MR after $1 \mathrm{~h}$ of aldosterone stimulation. In contrast, the MR antagonist, spironolactone, impaired the preinitiation complex assembly, because it allowed SRC1 recruitment, yet prevented RNA pol II binding to the transcriptional complex, providing an initial view of MR's regulatory mechanisms by antagonism. This finding, based on ChIP technology, differs from those obtained with glutathione $S$-transferase pull-down or mammalian 2-hybrid assays, using specific regions of MR or SRC1 rather than native full-length proteins, which have 
shown a lack of MR-SRC1 interaction after spironolactone exposure $(41,42)$. A more thorough investigation of the preinitiation complex assembly should aid in identifying gene-specific MR partners and in evaluating the influence and the dynamics of coregulator recruitment governing transcriptional regulation.

In summary, the present study provides a first genomewide mapping of the MR in human renal cells. By combining genomic, bioinformatic, and transcript analyses, we were able to define specific MREs and to identify novel MR target genes on which we correlated genomic MR recruitment and transcriptional activation. Our results constitute a first step toward a better understanding of the complex transcriptional regulation exerted by MR, including functional and dynamic interplay with other transcription factors. This research should contribute to future investigations exploring the pathophysiological role of MR.

The authors thank Stéphane Le Crom (Ecole Normale Supérieure, Institut de Biologie de l'ENS, IBENS, Plateforme Génomique, Paris, F-75005 France), Juliette Pouch (INSERM, U1024, Paris, F-75005 France), Sophie Lemoine (CNRS, UMR 8197, Paris, F-75005 France), and their genomic platform for their help in the genomic sequencing and initial analysis of the results; and Florian Nadal (INSERM U1185 and Assistance Publique-Hôpitaux de Paris, Service de Pharmacogénétique, Génétique Moléculaire et Hormonologie, Hôpital de Bicêtre, F-94275 Le Kremlin Bicêtre, France) for invaluable contributions to the initial analysis of the ChIP-seq data. This work was supported by grants from INSERM, Université Paris Sud and by Grant 11-BSV1-028-01 Agence Nationale de la Recherche (ANR). The ChIP-Seq was supported by the France Génomique national infrastructure, funded as part of the "Investissements d'Avenir" program managed by ANR contract ANR-10-INBS0009. F.L.B. is the recipient of a doctoral fellowship from Ministère de l'Enseignement Supérieur et de la Recherche (MESR), and J.A.K. received ANR postdoctoral fellowship 11BSV1-028-01. The authors declare no conflicts of interest.

\section{REFERENCES}

1. Palmer, L. G., Corthesy-Theulaz, I., Gaeggeler, H. P., Kraehenbuhl, J. P., and Rossier, B. (1990) Expression of epithelial Na channels in Xenopus oocytes. J. Gen. Physiol. 96, 23-46

2. Viengchareun, S., Le Menuet, D., Martinerie, L., Munier, M., Pascual-Le Tallec, L., and Lombès, M. (2007) The mineralocorticoid receptor: insights into its molecular and (patho)physiological biology. Nucl. Recept. Signal. 5, e012

3. Robert-Nicoud, M., Flahaut, M., Elalouf, J. M., Nicod, M., Salinas, M., Bens, M., Doucet, A., Wincker, P., Artiguenave, F., Horisberger, J. D., Vandewalle, A., Rossier, B. C., and Firsov, D. (2001) Transcriptome of a mouse kidney cortical collecting duct cell line: effects of aldosterone and vasopressin. Proc. Natl. Acad. Sci. USA 98, 2712-2716

4. Fakitsas, P., Adam, G., Daidié, D., van Bemmelen, M. X., Fouladkou, F., Patrignani, A., Wagner, U., Warth, R., Camargo, S. M., Staub, O., and Verrey, F. (2007) Early aldosterone-induced gene product regulates the epithelial sodium channel by deubiquitylation. J. Am. Soc. Nephrol. 18, 1084-1092

5. Sekizawa, N., Yoshimoto, T., Hayakawa, E., Suzuki, N., Sugiyama, T., and Hirata, Y. (2011) Transcriptome analysis of aldosterone-regulated genes in human vascular endothelial cell lines stably expressing mineralocorticoid receptor. Mol. Cell. Endocrinol. 341, 78-88

6. Johnson, J.P. (1992) Cellular mechanisms of action of mineralocorticoid hormones. Pharmacol. Ther. 53, 1-29

7. Pearce, D., Bhargava, A., and Cole, T. J. (2003) Aldosterone: its receptor, target genes, and actions. Vitam. Horm. 66, 29-76

8. Chen, S. Y., Bhargava, A., Mastroberardino, L., Meijer, O. C., Wang, J., Buse, P., Firestone, G. L., Verrey, F., and Pearce, D. (1999) Epithelial sodium channel regulated by aldosterone-induced protein sgk. Proc. Natl. Acad. Sci. USA 96, 2514-2519

9. Ziera, T., Irlbacher, H., Fromm, A., Latouche, C., Krug, S. M., Fromm, M., Jaisser, F., and Borden, S. A. (2009) Cnksr3 is a direct mineralocorticoid receptor target gene and plays a key role in the regulation of the epithelial sodium channel. FASEB J. 23, 3936-3946

10. Deppe, C. E., Heering, P. J., Viengchareun, S., Grabensee, B., Farman, N., and Lombès, M. (2002) Cyclosporine a and FK506 inhibit transcriptional activity of the human mineralocorticoid receptor: a cell-based model to investigate partial aldosterone resistance in kidney transplantation. Endocrinology 143, 1932-1941

11. Viengchareun, S., Kamenicky, P., Teixeira, M., Butlen, D., Meduri, G., Blanchard-Gutton, N., Kurschat, C., Lanel, A., Martinerie, L., Sztal-Mazer, S., Blot-Chabaud, M., Ferrary, E., Cherradi, N., and Lombès, M. (2009) Osmotic stress regulates mineralocorticoid receptor expression in a novel aldosterone-sensitive cortical collecting duct cell line. Mol. Endocrinol. 23, 1948-1962

12. Prié, D., Friedlander, G., Coureau, C., Vandewalle, A., Cassingéna, R., and Ronco, P. M. (1995) Role of adenosine on glucagon-induced cAMP in a human cortical collecting duct cell line. Kidney Int. 47, $1310-1318$

13. Jourdren, L., Bernard, M., Dillies, M. A., and Le Crom, S. (2012) Eoulsan: a cloud computing-based framework facilitating high throughput sequencing analyses. Bioinformatics 28, 1542-1543

14. Langmead, B., Trapnell, C., Pop, M., and Salzberg, S. L. (2009) Ultrafast and memory-efficient alignment of short DNA sequences to the human genome. Genome Biol. 10, R25

15. Li, H., Handsaker, B., Wysoker, A., Fennell, T., Ruan, J., Homer, N., Marth, G., Abecasis, G., and Durbin, R.; 1000 Genome Project Data Processing Subgroup. (2009) The Sequence Alignment/Map format and SAMtools. Bioinformatics 25, 2078-2079

16. Zhang, Y., Liu, T., Meyer, C. A., Eeckhoute, J., Johnson, D. S., Bernstein, B. E., Nusbaum, C., Myers, R. M., Brown, M., Li, W., and Liu, X. S. (2008) Model-based analysis of ChIP-Seq (MACS). Genome Biol. 9, R137

17. Feng, J., Liu, T., Qin, B., Zhang, Y., and Liu, X. S. (2012) Identifying ChIP-seq enrichment using MACS. Nat. Protoc. 7, 1728-1740

18. Sandelin, A., and Wasserman, W. W. (2004) Constrained binding site diversity within families of transcription factors enhances pattern discovery bioinformatics. J. Mol. Biol. 338, 207-215

19. Crooks, G. E., Hon, G., Chandonia, J. M., and Brenner, S. E. (2004) WebLogo: a sequence logo generator. Genome Res. 14, 1188-1190

20. Hudson, W. H., Youn, C., and Ortlund, E. A. (2014) Crystal structure of the mineralocorticoid receptor DNA binding domain in complex with DNA. PLOS ONE 9, e107000

21. Métivier, R., Penot, G., Hübner, M. R., Reid, G., Brand, H., Kos, M., and Gannon, F. (2003) Estrogen receptor-alpha directs ordered, cyclical, and combinatorial recruitment of cofactors on a natural target promoter. Cell 115, 751-763

22. Rossier, B. C., Canessa, C. M., Schild, L., and Horisberger, J. D. (1994) Epithelial sodium channels. Curr. Opin. Nephrol. Hypertens. 3, 487-496

23. Petrovich, E., Asher, C., and Garty, H. (2014) Induction of FKBP51 by aldosterone in intestinal epithelium. J. Steroid Biochem. Mol. Biol. 139, 78-87

24. Náray-Fejes-Tóth, A., Boyd, C., and Fejes-Tóth, G. (2008) Regulation of epithelial sodium transport by promyelocytic leukemia zinc finger protein. Am. J. Physiol. Renal Physiol. 295, F18-F26

25. Gumz, M. L., Stow, L. R., Lynch, I. J., Greenlee, M. M., Rudin, A., Cain, B. D., Weaver, D. R., and Wingo, C. S. (2009) The circadian clock protein period 1 regulates expression of the renal epithelial sodium channel in mice. J. Clin. Invest. 119, 2423-2434

26. Richards, J., Jeffers, L. A., All, S. C., Cheng, K. Y., and Gumz, M. L. (2013) Role of Perl and the mineralocorticoid receptor in the coordinate regulation of $\alpha \mathrm{ENaC}$ in renal cortical collecting duct cells. Front. Physiol. 4, 253

27. Richards, J., Ko, B., All, S., Cheng, K. Y., Hoover, R. S., and Gumz, M. L. (2014) A role for the circadian clock protein Perl in the regulation of the $\mathrm{NaCl}$ co-transporter (NCC) and the with-no-lysine kinase (WNK) cascade in mouse distal convoluted tubule cells. J. Biol. Chem. 289, 11791-11806

28. Ueda, K., Fujiki, K., Shirahige, K., Gomez-Sanchez, C. E., Fujita, T., Nangaku, M., and Nagase, M. (2014) Genome-wide analysis of murine renal distal convoluted tubular cells for the target genes of mineralocorticoid receptor. Biochem. Biophys. Res. Commun. 445, 132-137 
29. Dakour, J., Li, H., and Morrish, D. W. (1997) PL48: a novel gene associated with cytotrophoblast and lineage-specific HL-60 cell differentiation. Gene 185, 153-157

30. Amasaki, Y., Miyatake, S., Arai, N., and Arai, K. (2000) Regulation of nuclear factor of activated T-cell family transcription factors during T-cell development in the thymus. J. Allergy Clin. Immunol. 106, S1-S9

31. Wang, X., Zamolyi, R. Q., Zhang, H., Pannain, V. L., Medeiros, F., Erickson-Johnson, M., Jenkins, R. B., and Oliveira, A. M. (2010) Fusion of HMGA1 to the LPP/TPRG1 intergenic region in a lipoma identified by mapping paraffin-embedded tissues. Cancer Genet. Cytogenet. 196, 64-67

32. Hou, C., and Corces, V. G. (2012) Throwing transcription for a loop: expression of the genome in the 3D nucleus. Chromosoma 121, 107-116

33. Li, G., Cai, L., Chang, H., Hong, P., Zhou, Q., Kulakova, E. V., Kolchanov, N. A., and Ruan, Y. (2014) Chromatin interaction analysis with paired-end tag (ChIA-PET) sequencing technology and application. BMC Genomics $\mathbf{1 5}$ (suppl 12), S11

34. Pearce, D. (2001) The role of SGK1 in hormone-regulated sodium transport. Trends Endocrinol. Metab. 12, 341-347

35. Rubel, C. A., Lanz, R. B., Kommagani, R., Franco, H. L., Lydon, J. P., and DeMayo, F. J. (2012) Research resource: genome-wide profiling of progesterone receptor binding in the mouse uterus. Mol. Endocrinol. 26, 1428-1442

36. Pan, D., Kocherginsky, M., and Conzen, S. D. (2011) Activation of the glucocorticoid receptor is associated with poor prognosis in estrogen receptor-negative breast cancer. Cancer Res. 71, 6360-6370
37. Hu, S., Yao, G., Guan, X., Ni, Z., Ma, W., Wilson, E. M., French, F. S., Liu, Q., and Zhang, Y. (2010) Research resource: Genome-wide mapping of in vivo androgen receptor binding sites in mouse epididymis. Mol. Endocrinol. 24, 2392-2405

38. Need, E. F., Selth, L. A., Harris, T. J., Birrell, S. N., Tilley, W. D., and Buchanan, G. (2012) Research resource: interplay between the genomic and transcriptional networks of androgen receptor and estrogen receptor $\alpha$ in luminal breast cancer cells. Mol. Endocrinol. 26, 1941-1952

39. Polman, J. A., Welten, J. E., Bosch, D. S., de Jonge, R. T., Balog, J., van der Maarel, S. M., de Kloet, E. R., and Datson, N. A. (2012) A genome-wide signature of glucocorticoid receptor binding in neuronal PC12 cells. BMC Neurosci. 13, 118

40. Ratman, D., Vanden Berghe, W., Dejager, L., Libert, C., Tavernier, J., Beck, I. M., and De Bosscher, K. (2013) How glucocorticoid receptors modulate the activity of other transcription factors: a scope beyond tethering. Mol. Cell. Endocrinol. 380, 41-54

41. Hellal-Levy, C., Fagart, J., Souque, A., Wurtz, J. M., Moras, D., and Rafestin-Oblin, M. E. (2000) Crucial role of the H11-H12 loop in stabilizing the active conformation of the human mineralocorticoid receptor. Mol. Endocrinol. 14, 1210-1221

42. Fagart, J., Hillisch, A., Huyet, J., Bärfacker, L., Fay, M., Pleiss, U., Pook, E., Schäfer, S., Rafestin-Oblin, M. E., and Kolkhof, P. (2010) A new mode of mineralocorticoid receptor antagonism by a potent and selective nonsteroidal molecule. J. Biol. Chem. 285, 29932-29940

Received for publication April 3, 2015. Accepted for publication May 22, 2015. 